\title{
Z and t Distributions in Hypothesis Testing: Unequal Division of Type I Risk
}

Ceyhun Ozgur

Valparaiso University, ceyhun.ozgur@valpo.edu

Follow this and additional works at: http://digitalcommons.wayne.edu/jmasm

\section{Recommended Citation}

Ozgur, Ceyhun (2016) "Z and t Distributions in Hypothesis Testing: Unequal Division of Type I Risk," Journal of Modern Applied Statistical Methods: Vol. 15 : Iss. 1 , Article 24.

DOI: $10.22237 /$ jmasm/1462076580

Available at: http://digitalcommons.wayne.edu/jmasm/vol15/iss1/24

This Regular Article is brought to you for free and open access by the Open Access Journals at DigitalCommons@WayneState. It has been accepted for inclusion in Journal of Modern Applied Statistical Methods by an authorized editor of DigitalCommons@WayneState. 


\title{
Z and t Distributions in Hypothesis Testing: Unequal Division of Type I Risk
}

\author{
Cover Page Footnote \\ Special thanks go to Yang Li, Zachariah Hughes, and Taylor Colliau for their help on this project.
}




\title{
$Z$ and $\mathbf{t}$ Distributions in Hypothesis Testing: Unequal Division of Type I Risk
}

\author{
Ceyhun O. Ozgur \\ Valparaiso University \\ Valparaiso, Indiana
}

Introductory statistics texts have given extensive coverage to two-sided inferences. All texts that were surveyed give significant coverage to one-sided hypothesis tests. Very few discussed the possibility of one-sided interval estimation at all. Even fewer mentioned so in any detail the possibility of dividing the risk of a type I error unequally between the tails for a two-sided confidence interval. None of the textbooks that were reviewed even considered the possibility of unequal tails for two-sided hypothesis tests. In this paper, we suggest that all statistics courses and texts should cover both one-sided tests and confidence intervals. Furthermore, coverage should also be given to unequal division of the nominal risk of a type I error for both hypothesis tests and confidence intervals. Examples are provided for both situations.

Keywords: $\quad$ Statistical Inference, Division of Type I error risk, $Z$ distribution, Hypothesis testing, $t$ distribution, Unequal Division of Type I Error

\section{Introduction}

One-sample $Z$ and $t$ tests are far less robust to departures from normality than are two sample tests. This has been known for over a century now. Hence, these techniques are usually taught only for pedagogical purposes. All introductory statistics textbooks cover two-sided hypothesis tests and confidence intervals with alpha split equally between the tails. All gave extensive coverage to one-sided hypothesis tests but only a few mention one-sided confidence intervals. Our research surveyed some of the most reputable textbooks used in Introductory Business Statistics courses. Only one textbook that was surveyed considered the possibility of splitting alpha unequally between the tails for a confidence interval and none did so for hypothesis tests. Since there is a one-to-one correspondence between hypothesis tests and confidence intervals, a strong case can be made that

Dr. Ozgur is a Professor of Information and Decision Science. Email him at: Ceyhun.Ozgur@valpo.edu. 


\section{CEYHUN O. OZGUR}

all texts should give detailed coverage to one-sided confidence intervals. Practical examples are easy to develop and the intervals are simple to construct. Therefore, there is no justification for omitting their coverage.

In situations where both tails were actually of interest, all of the textbooks surveyed split alpha equally between the tails in hypothesis testing situations. Ramsey (1990) mentioned in his paper that instead of running a one-tailed test at the .05 level, the test could be ran at the .04 level. This would be more powerful than a two-tailed test ran at the .05 level because, for results in the predicted direction, such a test would be equivalent to a one-tailed test at the .025 level. However, results which come out in the opposite direction beyond a .01 probability could be rejected and taken as evidence against any previous knowledge about an outcome in the predicted direction. Of all the texts that were surveyed, only Harnett and Soni (1991) mentioned the possibility of an unequal split for confidence intervals and they only do so in one sentence. Students would develop a better understanding of the rationale underlying the choice of alpha if they were given a broad spectrum of possibilities for splitting it between the tails. This is particularly true for business students when examples can associate specific costs with type I errors. In practice, the costs associated with a type I error on one side may be different from the costs on the other side. Therefore, the risks should have been split proportionately to the costs. In the next section two examples will be provided to demonstrate the unequal split of $\alpha$ between the two tails. The example applications involve a service and a manufacturing scenario respectively. We surveyed many textbooks and the table of what we found regarding the uneven division of alpha can be found in the Table 1.

\section{Service Application}

Suppose that a fast food restaurant with significant sales from coffee customers at the drive-thru window is analyzing coffee temperature. The target temperature for a coffee cup is 175 degrees Fahrenheit with a temperature tolerance of \pm 5 degrees. If a cup of coffee is too hot or in other words, if it is warmer than 180 degrees (above the upper tolerance) and someone gets burned, there is the potential for a very costly lawsuit, possibly a settlement for $\$ 2.4$ million. On the other hand, if the cup temperature is too cool, below the lower tolerance of 170 degrees, then there is likely to be lost sales and possible customer erosion in other product areas. The analyst estimates lost profits from declining sales to be $\$ 800,000$. In this scenario neither a one-tailed inference nor a two-sided inference with equal tails would be logically appropriate. 


\section{UNEQUAL DIVISION OF TYPE I RISK}

Table 1. Statistical books with coverage of $Z \& t$ tests and unequal division of alpha

\begin{tabular}{|c|c|c|c|c|c|}
\hline Authors & Publishers & $\begin{array}{l}\text { Publication } \\
\text { Date/Edition }\end{array}$ & Book Title & $Z \& t$ Test & $\begin{array}{r}\text { Unequal Division } \\
\text { of Alpha }\end{array}$ \\
\hline A.D. Aczel & McGraw-Hill-Irwin & $1999,4^{\text {th }}$ edition & Complete Business Statistics & Yes & No \\
\hline $\begin{array}{l}\text { D. R. Anderson, D.J. } \\
\text { Sweeney, \& T. Williams }\end{array}$ & Southwestern & $2009,10^{\text {th }}$ edition & $\begin{array}{l}\text { Statistics for Business and } \\
\text { Economics }\end{array}$ & Yes & No \\
\hline $\begin{array}{l}\text { D. R. Anderson, D.J. } \\
\text { Sweeney, \& T. Williams }\end{array}$ & Southwestern & $1998,7^{\text {th }}$ edition & $\begin{array}{l}\text { Quantitative Methods for } \\
\text { Business }\end{array}$ & Yes & No \\
\hline M. Berenson, \& D.M. Levine & Prentice-Hall & $1999,7^{\text {th }}$ edition & Basic Business Statistics & Yes & No \\
\hline $\begin{array}{l}\text { M. Berenson, D. Levine, \& } \\
\text { T.C. Krehbiel }\end{array}$ & Prentice-Hall & $2000,2^{\text {nd }}$ edition & $\begin{array}{l}\text { Business Statistics: A First } \\
\text { Course }\end{array}$ & Yes & No \\
\hline K. Black, \& D. Eldredge & Southwestern & $2002,1^{\text {st }}$ edition & $\begin{array}{l}\text { Business and Economic } \\
\text { Statistics }\end{array}$ & Yes & No \\
\hline $\begin{array}{l}\text { B. Bowerman \& R. } \\
\text { O'Connell, \& J.B. Orris }\end{array}$ & McGraw-Hill-Irwin & $2004,1^{\text {st }}$ edition & $\begin{array}{l}\text { Essentials of Business } \\
\text { Statistics }\end{array}$ & Yes & No \\
\hline Y. Chou & Elsevier & $1989,1^{\text {st }}$ edition & $\begin{array}{l}\text { Statistical Analysis for } \\
\text { Business and Economics }\end{array}$ & Yes & No \\
\hline W. Cochran, \& G. Cox & John Wiley \& Sons & $1992,2^{\text {nd }}$ edition & Experimental Designs & $\begin{array}{l}t \text {-test: Yes } \\
Z \text {-test: No }\end{array}$ & No \\
\hline D.P. Doane, \& L.E. Seward & McGraw-Hill & $2016,5^{\text {th }}$ edition & $\begin{array}{l}\text { Applied Statistics in Business } \\
\text { and Economics }\end{array}$ & Yes & No \\
\hline D.L. Harnett \& A.K. Soni & Addison-Wesley & $1991,1^{\text {st }}$ edition & $\begin{array}{l}\text { Statistical Methods for } \\
\text { Business and Economics }\end{array}$ & Yes & Yes \\
\hline J. Hawkes, \& W. Marsh & Hawkes Publishing & $2005,2^{\text {nd }}$ edition & Discovering Statistics & Yes & No \\
\hline D.H. Hildebrand \& R.L. Ott & Brooks/Cole & $1998,4^{\text {th }}$ edition & $\begin{array}{l}\text { Statistical Thinking for } \\
\text { Managers }\end{array}$ & Yes & No \\
\hline $\begin{array}{l}\text { G. Keller, B. Warrack, \& H. } \\
\text { Bartel }\end{array}$ & Wadsworth & $1998,1^{\text {st }}$ edition & $\begin{array}{l}\text { Statistics for Management } \\
\text { and Economics }\end{array}$ & Yes & No \\
\hline R.I. Levin, \& D.S. Rubin & Prentice-Hall & $1994,6^{\text {th }}$ edition & Statistics for Management & Yes & No \\
\hline $\begin{array}{l}\text { D.M. Levine, T. C. Krehbiel, } \\
\text { M.L. Berenson }\end{array}$ & Prentice-Hall & $2000,2^{\text {nd }}$ edition & Business Statistics & Yes & No \\
\hline
\end{tabular}

Table 1 continued on next page 


\section{CEYHUN O. OZGUR}

Table 1 cont. Statistical books with coverage of $Z \& t$ tests and unequal division of alpha

\begin{tabular}{|c|c|c|c|c|c|}
\hline Authors & Publishers & $\begin{array}{l}\text { Publication } \\
\text { Date/Edition }\end{array}$ & Book Title & $\begin{array}{l}Z \& t \\
\text { Test }\end{array}$ & $\begin{array}{r}\text { Unequal } \\
\text { Division of } \\
\text { Alpha }\end{array}$ \\
\hline R.D. Mason, \& D.A. Lind & Irwin & $1993,8^{\text {th }}$ edition & $\begin{array}{l}\text { Statistical Techniques in Business and } \\
\text { Economics }\end{array}$ & Yes & No \\
\hline $\begin{array}{l}\text { J.T. McClave, P.G. Benson, } \\
\text { \& T. Sincich }\end{array}$ & Prentice-Hall & $2011,11^{\text {th }}$ edition & Statistics for Business and Economics & Yes & No \\
\hline $\begin{array}{l}\text { G. Meek, H. Taylor, K. } \\
\text { Dunning, \& K. Klafehn }\end{array}$ & Allyn \& Bacon & $1987,1^{\text {st }}$ edition & Business Statistics & Yes & No \\
\hline G. Meek, \& S. J. Turner & Houghton \& Mifflin & $1983,1^{\text {st }}$ edition & Statistical Analysis for Business Decisions & Yes & No \\
\hline W. Mendenhall \& R. Beaver & PWS-Kent & $1992,3^{\text {rd }}$ edition & A Course in Business Statistics & Yes & No \\
\hline $\begin{array}{l}\text { J. Neter, M. Kutner, C. } \\
\text { Nachtsheim, \& W. } \\
\text { Wasserman }\end{array}$ & McGraw-Hill & $1996,4^{\text {th }}$ edition & Applied Linear Statistical Models & Yes & No \\
\hline $\begin{array}{l}\text { J. Neter, W Wasserman, } \\
\text { G.A. Whitmore }\end{array}$ & Allyn \& Bacon & $1993,4^{\text {th }}$ edition & Applied Statistics & Yes & No \\
\hline P. Newbold & Prentice-Hall & $1991,3^{\text {rd }}$ edition & Statistics for Business and Economics & Yes & No \\
\hline $\begin{array}{l}\text { P. Newbold, W.L. Carlson, } \\
\text { \& B. Thorne }\end{array}$ & Prentice-Hall & $2007,6^{\text {th }}$ edition & Statistics for Business and Economics & Yes & No \\
\hline M. Pelosi, \& T. Sandifer & John Wiley \& Sons & $2002,2^{\text {nd }}$ edition & Doing Statistics for Business with Excel & Yes & No \\
\hline H. Scheffe & John Wiley \& Sons & $\begin{array}{l}1999,1^{\text {st }} \text { edition } \\
\text { reprinted }\end{array}$ & The Analysis of Variance & No & No \\
\hline A.F. Siegel & Irwin & $1990,1^{\text {st }}$ edition & Practical Business Statistics & Yes & No \\
\hline T. Sincich & Kraus & $1996,5^{\text {th }}$ edition & Business Statistics by Example & Yes & No \\
\hline $\begin{array}{l}\text { C. Watson, P. Billingsley, } \\
\text { D.J. Croft, \& D. } \\
\text { Huntsberger }\end{array}$ & Allyn \& Bacon & $1990,4^{\text {th }}$ edition & Statistics for Management and Economics & Yes & No \\
\hline R. M. Weiers & Duxbury & $2005,5^{\text {th }}$ edition & Introduction to Business Statistics & Yes & No \\
\hline
\end{tabular}

Note: Most textbooks that were surveyed covered $Z$ and $t$ tests, as well as 1 and 2 sided hypothesis testing. 


\section{UNEQUAL DIVISION OF TYPE I RISK}

\section{Manufacturing Application}

Consider a manufacturing process in which the first operation is to cut stainless steel rods into lengths of two feet prior to machining and threading operations. The nominal length for each piece is two feet. Customer specifications allow \pm 0.050 inches. If a part is oversized, that is, greater than 24.050 , it can be "reworked" at a cost of $\$ 0.50$ while undersized pieces, those less than 23.950, must be scrapped at a cost of $\$ 2.00$. In this example the cost of a steel rod being longer than 24.05 is lower than the cost of a steel rod below the lower specification limit. This would be an example where dividing the risk of a type I error equally between the tails is not a reasonable choice nor is a one-sided approach.

\section{Literature Review}

As mentioned earlier, few authors discuss one-sided confidence intervals. Only one to my knowledge even considers the possibility of an asymmetric two-sided confidence interval for means. None considered dividing alpha unequally between the tails in two-sided hypothesis tests. Hildebrand and Ott (1998) presented a brief discussion of one-sided confidence intervals for a mean, providing an equation and a very brief example. Neter, Wasserman and Whitmore (1993) provided an optional section on one-sided confidence intervals with some development and examples. Meek and Turner (1983) provided a detailed example of one-sided intervals with cost considerations and discussion. The best and most detailed coverage of one-sided confidence intervals is in Siegel (1997). Siegel (1997) also included a discussion and examples of one-sided prediction intervals.

Of the texts that this paper surveyed, only Harnett and Soni (1991) mentioned the possibility of splitting alpha unequally in a two-sided situation. They provide a brief discussion about asymmetric two-sided confidence intervals and the related cost considerations; however, they then dismiss the idea on the basis that the costs are not easily obtained (Harnett \& Soni, 1991). Of the thirtyone texts surveyed this was the only one that considered the possibility of an unequal split in two-sided hypothesis testing situations.

\section{Asymmetric Two-Sided Confidence Intervals for a Population Mean}

One-sided confidence intervals are very easy to construct. All textbooks covered one-sided tests of hypotheses. Thus, due to the correspondence between confidence intervals and hypotheses tests, it is simply proposed that all 


\section{CEYHUN O. OZGUR}

introductory statistics texts should cover one-sided confidence intervals as well as one-sided tests of hypotheses. Coverage of one-sided confidence intervals can be used as an important tool to reinforce the explanation of one-sided tests of hypotheses since both one-sided hypothesis tests and the one sided confidence intervals involve the concept of allocating the risk of a type one error to only one tail.

It is proposed to restrict the discussion to the situation in which it is desirable, based on cost considerations, to construct a two-sided confidence interval with unequal tails. The development of the equations with the following remarks was prefaced. If a desired value is not contained in the confidence interval it is assumed that corrective action is to be taken. If the desired value for $\mu$ is below the lower limit of the confidence interval the mean would be adjusted downward. If the true mean is actually desired this will result in an increase of "small units". Correspondingly, if the desired value for $\mu$ is greater than the upper limit of the confidence interval, an attempt would be made to increase the mean, resulting in an increase of "large units" if the true mean is desired.

The mathematics of constructing such intervals for population means is quite simple. Once the decision has been made regarding how alpha is to be divided, the appropriate percentage points from either the standard normal or the $t$-table is selected. If the population standard deviation is known, the standard normal $(Z)$ distribution should be used. However, if the population standard deviation is estimated, $t$ distribution should be used. Assume that it has been decided to place $p \alpha, 0 \leq p \leq 1$, in the upper tail and $(1-p) \alpha, 0 \leq p \leq 1$, in the lower tail. Assuming that $\sigma$ is known, the resulting confidence limits are given by Equation 1.

$$
\begin{aligned}
& \mathrm{UL}=\bar{X}+Z_{(p) \alpha} \frac{\sigma}{\sqrt{n}} \\
& \text { and } \\
& \mathrm{LL}=\bar{X}-Z_{(1-p) \alpha} \frac{\sigma}{\sqrt{n}}
\end{aligned}
$$

If the population standard deviation is not known, Equation 1 can be modified by replacing the $Z$-statistic with an appropriate $t$-statistic with $n-1$ degrees of freedom, where $n$ represents the sample size. If the population standard deviation is not known the resulting confidence limits are given by Equation 2 . 


\section{UNEQUAL DIVISION OF TYPE I RISK}

$$
\begin{aligned}
& \mathrm{UL}=\bar{X}+t_{(p) \alpha, n-1} \frac{s}{\sqrt{n}} \\
& \text { and } \\
& \mathrm{LL}=\bar{X}-t_{(1-p) \alpha, n-1} \frac{s}{\sqrt{n}}
\end{aligned}
$$

If $c_{1}$ represents the cost associated with an unnecessary decrease in $\mu$ and $c_{2}$ is the cost associated with an unnecessary increase in $\mu$, and then setting

$$
p=\frac{c_{1}}{\left(c_{1}+c_{2}\right)}
$$

It will provide a split that equalizes the expected costs between the two tails. For $c_{1}$ equal to zero, or alternatively $c_{2}=0$, it becomes a one-sided interval, while $c_{1}=c_{2}$ gives the standard two-sided symmetric confidence interval for a mean.

\section{Service Application Revisited}

Let us refer to the service example described earlier involving the temperature of coffee. In that situation, it could be stated that a type I error has occurred if the actual average temperature of cups of coffee is on target at 175 degrees, but a confidence interval indicates that the target value is not contained within the limits. There are two possible ways in which the interval may not contain the target value:

1. If the entire confidence interval is above 175 degrees, then the process mean would be adjusted downward. This type of miss is defined as the "low side" miss.

2. If the entire confidence interval falls below the target value of 175 degrees, then the process mean would be adjusted upward. This is defined as the "high side" miss.

Of course, both types of adjustments given above are erroneous. The "low side" miss would result in unnecessarily lowering the temperature, resulting in temperatures that are too cool. The "high side" miss would result in temperatures that are too hot. As mentioned earlier, if the average coffee temperature is too cool, then there is likely to be lost sales estimated at $\$ 800,000$. If the average 


\section{CEYHUN O. OZGUR}

coffee temperature is too hot and a customer gets burned, the estimated cost of a lawsuit is $\$ 2,400,000$. Since an unnecessary downward adjustment is three times less costly than an unnecessary upward adjustment, it would be preferred to miss on the "low side" as opposed to missing on the "high side". Since $c_{1}=\$ 800,000$ and $c_{2}=\$ 2,400,000$,

$$
p=\frac{c_{1}}{\left(c_{1}+c_{2}\right)}=\frac{800,000}{(800,000+2,400,000)}=\frac{1}{4}=.25 ; 1-p=.75
$$

For illustrative purposes assume that $\sigma$ is known and the population standard deviation is 1.2 degrees, the confidence level, $1-\alpha$, is chosen to be 0.90 , and a sample of 4 cups of coffee resulted in a mean temperature of 174.1 degrees. The appropriate $Z$ statistic values are then determined from the normal $Z$ table. Since $p(\alpha)=0.25 * 0.10=.025$ and $(1-p) \alpha=0.75 * 0.10=.075$, the corresponding $Z$-values are $Z_{0.025}=1.96$ and $Z_{0.075}=1.44$ for the upper limit and lower limit respectively. The resulting confidence limits are calculated as follows:

$$
\begin{aligned}
& \mathrm{UL}=174.1+1.96\left(\frac{1.2}{\sqrt{4}}\right)=175.276 \text { degrees } \\
& \mathrm{LL}=174.1-1.44\left(\frac{1.2}{\sqrt{4}}\right)=173.236 \text { degrees }
\end{aligned}
$$

If the traditional two-sided confidence interval is employed with an equal split of alpha between the two tails, using $Z_{.05}=1.645$ on both sides of the confidence interval, resulting in an upper limit and a lower limit of 175.09 and 173.11 respectively. If the estimated costs of $c_{1}$ and $c_{2}$ are accurate, then compared to the asymmetric limits, symmetric limits will not provide enough coverage on the upper tail and will provide unnecessarily high coverage on the lower tail. Equation 3 provides the expected cost of a type I error where $\mathrm{EC}=$ Expected Cost of type I error.

$$
\mathrm{EC}=p(\alpha) c_{2}+(1-p)(\alpha)\left(c_{1}\right)
$$

Based on the asymmetric limits, 


\section{UNEQUAL DIVISION OF TYPE I RISK}

$$
\mathrm{EC}=(.25)(.10)(2,400,000)+(.75)(.10)(800,000)=60,000+60,000=\$ 120,000 \text {. }
$$

On the other hand, based on the symmetric limits,

$$
\mathrm{EC}=(.5)(.10)(2,400,000)+(.5)(.10)(800,000)=120,000+40,000=\$ 160,000
$$

Therefore, if the symmetric confidence limits are used in lieu of asymmetric limits, the decision maker has to incur an additional expected cost of $\$ 40,000$ $(160,000-120,000)$.

In this situation it is also possible to construct a one-sided confidence interval by constructing only the upper control limit or by constructing only the lower control limit. Since the cost of being above the upper control limit is greater than the cost of being below the lower control limit, the one-sided interval is employed by determining only the upper limit. In this case, $Z_{.10}$ equals 1.28 and the upper limit is calculated as follows:

$$
\mathrm{UL}=174.1+1.28 \frac{1.2}{\sqrt{4}}=174.868
$$

However, if the one-sided confidence interval is employed in lieu of asymmetric two-sided limits,

$$
E C=(.10)(2,40,000)=\$ 240,000 \text {. }
$$

If the one-sided confidence limit is used in lieu of asymmetric limits, the decisionmaker has to incur an additional expected cost of $\$ 120,000(240,000-120,000)$.

\section{Production Application Revisited}

This situation was chosen to involve stainless steel rods that were mentioned earlier. In that situation a "type I error" would be considered to have occurred if the process is set up correctly and is yielding average lengths at or very close to 24 inches, but a confidence interval indicates otherwise. If the interval does not contain the value 24 on the "low side", i.e., the entire interval is above 24 , the process mean would be adjusted downward, while if it misses on the "high side" it would be adjusted upward. Either adjustment would actually be a mistake and would result in production of some discrepant parts. Adjusting downward would 


\section{CEYHUN O. OZGUR}

result in some undersized parts at a cost of $\$ 2.00$ each while adjusting upward would produce some oversized parts that will need to be reworked at a cost of $\$ 0.50$ each. Since an unnecessary downward adjustment is four times as costly as an unnecessary upward adjustment, that would be preferred if it was to occur less often. In fact, in order to balance expected costs, it is preferred to make unnecessary downward adjustments only one quarter as often as unnecessary upward ones. Therefore, letting $c_{1}=2.00$ and $c_{2}=0.50$ gives

$$
p=\frac{2.00}{(2.00+.50)} 0.8, \text { and } 1-p=0.2
$$

The following assumptions were made in order to construct the confidence interval. For illustrative purposes assume that $\sigma$ is known to equal 0.020 inches, the confidence level, $(1-\alpha)$, is chosen to be 0.95 , and a sample of 16 items gave a mean of 24.008 inches. The next step was to determine the appropriate values from the normal $Z$ table to be used.

$$
p(\alpha)=0.8 * 0.05=.04 \text { and }(1-p) \alpha=0.2 * 0.05=.01 \text {. The corresponding }
$$
$Z$-values for the upper and lower limits respectively are $Z_{0.04}=1.75$ and $Z_{0.01}=2.326$. The resulting confidence limits are:

$$
\begin{aligned}
& \mathrm{UL}=24.008+1.75(0.020 / 4)=24.0168 \mathrm{in} . \\
& \mathrm{LL}=24.008-2.326(0.020 / 4)=23.9964 \mathrm{in} .
\end{aligned}
$$

There was no evidence to suggest that the mean is other than 24 and no adjustment would be made at this time.

If the traditional two-sided confidence interval with an equal split of alpha between the two tails used, $Z_{.025}=1.96$ is used on both sides of the confidence interval, resulting in an upper limit and lower limit of 24.0178 and 23.9982 respectively.

If assumed that $c_{1}$ and $c_{2}$ are appropriate cost estimates, then compared to the asymmetric limits, the symmetric limits result in unnecessarily high coverage of the upper tail and insufficient coverage of the lower tail. Utilizing Equation 3, the per part expected cost of a Type I error can be calculated based on the asymmetric limits as follows:

$$
\mathrm{EC}=(.8)(.05)(.50)+(.2)(.05)(2.0)=.02+.02=\$ .04
$$




\section{UNEQUAL DIVISION OF TYPE I RISK}

On the other hand, based on the symmetric limits the per part expected cost is:

$$
\mathrm{EC}=(.5)(.05)(.50)+(.5)(.05)(2.00)=.0125+.05=\$ .0625
$$

Therefore, if the symmetric confidence limits are used in lieu of the asymmetric limits, the decision maker has to incur an additional expected cost per part of $\$ .025(.0625-.04)$.

If the one-sided confidence interval was constructed by using only the lower control limit, $Z_{.05}=1.645$ would be used and the lower limit is calculated as follows: $\quad L L=24.008-1.645 \frac{.02}{\sqrt{16}}=23.9976$. However, if the one-sided confidence interval is utilized in lieu of asymmetric two-sided limits,

$$
\mathrm{EC}=(.05)(2.00)=\$ 0.10
$$

If the one-sided confidence limit is used in lieu of asymmetric limits, the decisionmaker has to incur an additional expected cost per part of $\$ .06(.10-.04)$.

\section{Unequal Tails for Two-Sided Hypothesis Tests about a Population Mean}

For two-sided hypothesis tests the approach is similar and one can use either the p-value approach with a nominal $\alpha$ or the usual comparison of a sample statistic ( $Z$ or $t$ ) to the appropriate critical value based on an unequal split of the nominal $\alpha$ between the two tails. Note that the confidence interval approach reacted to the position of $\mu_{o}$ relative to the sample mean while the hypothesis test approach reacted to the position of the sample mean relative to $\mu_{o}$. Therefore, the decision rule regarding the split of $\alpha$ between the tails is exactly opposite for the two approaches. That is, if $H_{o}$ is rejected incorrectly on the high side, the resulting action is to adjust the process downward. On the other hand, if $H_{o}$ is rejected incorrectly on the low side the process would be adjusted upward.

Let $c_{1}$ represent the cost of an unnecessary decrease in $\mu$, occurring when $H_{o}$ is rejected on the high side, and $c_{2}$ represented the similar cost of an unnecessary increase in $\mu$, occurring with a rejection on the low side. Then, for a given significance level of $\alpha$ it is supposed to put $(1-p) \alpha$ in the upper tail for the test procedure and $p \alpha$ in the lower tail in order to balance the expected costs of a type I error between them. Thus, a two-sided test with unequal costs in the rejection areas, for the hypotheses $H_{o}: \mu=\mu_{o}$ versus $H_{a}: \mu \neq \mu_{o}$, assuming $\sigma$ is known, one 


\section{CEYHUN O. OZGUR}

would reject $H_{o}$ if the calculated $Z$-value is either greater than $Z_{(1-p) \alpha}$ or less than $-Z_{p \alpha}$. Alternatively, $H_{o}$ is rejected. If either

$$
\bar{X}<\mu-Z_{p \alpha} \frac{\sigma}{\sqrt{n}} \text { or } \bar{X}>\mu+Z_{(1-p) \alpha} \frac{\sigma}{\sqrt{n}}
$$

Production Application Utilizing the same example as the one that was presented earlier when confidence intervals are discussed, the hypotheses: $H_{o}: \mu=24$ versus $H_{a}: \mu \neq 24$ is stated. As before, the information includes the following: $n=16, \sigma=0.020, \alpha=0.05, c_{1}=2.00, c_{2}=0.50$ and $\bar{X}=24.008$, $p=0.8$. Concluding that $\mu$ is less than 24 will result in adjusting the process upward, while concluding $\mu$ is greater than 24 results in a downward adjustment. Therefore, the null hypothesis would be rejected if either

$$
\begin{gathered}
\bar{X}>24+2.326(.020 / 4)=24.0116 \text { or if } \\
\bar{X}<24-1.750(.020 / 4)=23.9913
\end{gathered}
$$

Since the sample mean value of 24.008 is between the two numbers, $H_{o}$ could not be rejected alternatively,

$$
\begin{aligned}
& Z_{\text {calc }}=\frac{\bar{X}-\mu}{\frac{\sigma_{X}}{\sqrt{n}}} \\
& Z_{\text {calc }}=\frac{24.008-24}{\frac{.02}{\sqrt{16}}}=\frac{.008}{.005}=1.6
\end{aligned}
$$

Since $1.6<2.326$ and $1.6>-1.75, H_{0}$ cannot be rejected and is concluded that the mean length of steel rods does not appear to differ from 24 inches.

Service Application Based on the service example described earlier involving the temperature of coffee, recall that $c_{1}=\$ 800,000, c_{2}=\$ 2,400,000$, $n=4, \sigma=1.20, \alpha=0.10, \bar{X}=174.1$, and $p=.25$. Let's assume that the two-sided hypotheses are stated as follows: 


\section{UNEQUAL DIVISION OF TYPE I RISK}

$H_{o}: \mu=175$ versus $H_{a}: \mu \neq 175$. Concluding that $\mu$ is less than 175 will result in adjusting the process upward, while concluding that $\mu$ is greater than 175 results in a downward adjustment of the temperature. Therefore, the null hypothesis would be rejected if either

$$
\begin{aligned}
& \bar{X}>175+1.44(1.2 / 2)=175.864 \text { or if } \\
& \bar{X}<175-1.96(1.2 / 2)=173.824
\end{aligned}
$$

Since the sample mean value of 174.1 is between the two numbers, $H_{o}$ could not be rejected. Alternatively,

$$
Z_{\text {calc }}=\frac{\bar{X}-\mu}{\frac{\sigma_{X}}{\sqrt{n}}}=\frac{174.1-175}{\frac{1.2}{\sqrt{4}}}=\frac{-.90}{.6}=-1.5
$$

Since $-1.5<1.44$ and $-1.5>-1.96, H_{0}$ is not rejected, and conclude that the average temperature of a cup of coffee is not significantly different than 175 degrees.

\section{Future Research Considerations, Limitations and Conclusions}

Most introductory statistics texts fail to discuss one-sided confidence intervals and, other than a brief discussion without an example by Harnett and Soni (1991), none even consider the possibility of splitting $\alpha$ unequally between the two tails when the costs associated with the tails are different. One-sided confidence intervals should be standard coverage just as one-sided hypothesis tests are. Also, I believe that students should be made aware that the division of the type I risk between the tails should be decided by the costs rather than by convenience. In addition to the unequal division of type I error risk between the two tails for a single mean, that could also utilize this approach when testing a single proportion or a single variance, as well as testing the difference between two parameters. The latter case, though, is difficult to envision in a practical situation. Unfortunately, in many instances the consequences of committing a type I error cannot easily be expressed in dollar terms. In certain instances the difficulty of quantifying the cost of a type I error is the major drawback of this approach. There are many instances 


\section{CEYHUN O. OZGUR}

in which cost estimates of committing a type I error are not available or cannot be estimated. In other situations it is simply cannot be deciphered the cost of making a type I error above the upper control limit vs. cost of making a type I error below the lower control limit. In these situations, even though it is not ideal, it may still be better to utilize the asymmetric limits in lieu of the symmetric limits based on subjective considerations. However, the asymmetric limits and the unequal split of alpha work best when cost estimates $\left(c_{1}\right.$ and $\left.c_{2}\right)$ are available and are

reasonably accurate. A topic for further consideration is the impact of unequal tails on the type II error and on balancing expected costs with respect to it as well.

\section{Acknowledgements}

Special Thanks to Yang Li, Zachariah Hughes, and Taylor Colliau for their help in this research project.

\section{References}

Aczel, A. D., \& Sounderpandian J. (2002). Complete business statistics (5 $^{\text {th }}$ ed.). New York, NY: McGraw-Hill/Irwin.

Anderson, D. R., Sweeney, D. J., \& Williams, T. A. (2003a). Essentials of statistics for business and economics ( ${ }^{\text {rd }}$ ed.). Mason, $\mathrm{OH}$ : Southwestern.

Anderson, D. R., Sweeney, D. J., \& Williams. T. (2003). Modern business statistics with Microsoft Excel. Mason, OH: Southwestern.

Berenson, M. L., Levine, D. M., \& Krehbiel, T. C. (2003). Basic business statistics: Concepts and applications ( $9^{\text {th }}$ ed.). Upper Saddle River, NJ: Prentice Hall

Black, K. (2001). Business statistics: Contemporary decision making ( $3^{\text {rd }}$ ed.). Mason, $\mathrm{OH}$ : Southwestern.

Bowerman, B. L., \& O’Connell, R. T. (2007). Business statistics in practice (4th ed.). Boston, MA: McGraw-Hill/Irwin.

Carlson, W. L., Thorne, B. (1997). Applied statistical methods: For business, economics, and the social sciences. Upper Saddle River, NJ: Prentice Hall.

Chou, Y.-L. (1989). Statistical analysis for business and economics. New York, NY: Elsevier.

Cochran, W. G., \& Cox, G. M. (1957). Experimental designs (2 ${ }^{\text {nd }}$ ed.). New York, NY: J. Wiley \& Sons. 


\section{UNEQUAL DIVISION OF TYPE I RISK}

Doane, D. P., \& Seward, L. W. (2016). Applied statistics in business and economics $\left(5^{\text {th }}\right.$ ed.). New York, NY: McGraw-Hill.

Gitlow, H. S., Oppenheim, A. V., \& Oppenheim, R. (1995). Quality

management: Tools and methods for the improvement $\left(2^{\text {nd }}\right.$ ed.). Burr Ridge, IL: Irwin.

Gitlow, H. S., \& Levine, D. M. (2005). Six Sigma for green belts and champions: Foundations, DMAIC, tools, cases, and certification. Upper Saddle River, NJ: Pearson Education.

Harnett, D. L., \& Soni, A. K. (1991). Statistical methods for business and economics $\left(4^{\text {th }}\right.$ ed.). New York, NY: Addison-Wesley.

Hildebrand, D. H., \& Ott, R. L. (1998). Statistical thinking for managers ( $^{\text {th }}$ ed.). Pacific Grove, CA: Duxbury Press.

Keller, G., Warrack, B., \& Bartel, H. (1994). Statistics for management and economics: A systematic approach ( $3^{\text {rd }}$ ed.). Belmont, CA: Duxbury Press.

Kohler, H. (2002). Statistics for business and economics. Mason, $\mathrm{OH}$ :

Southwestern.

Levin, R. I., \& Rubin, D. S. (1994). Statistics for management (6 ${ }^{\text {th }}$ ed.). Englewood Cliffs, NJ: Prentice Hall.

Levine, D. M., Stephan, D., Krehbiel, T. C., \& Berenson, M. L. (2002).

Statistics for managers using Microsoft Excel ( $3^{\text {rd }}$ ed.). Upper Saddle River, NJ:

Prentice Hall.

Mason, R. D., \& Lind, D. A. (1993). Statistical techniques in business and economics $\left(8^{\text {th }}\right.$ ed.). Homewood, IL: Irwin.

McClave, J. T., Benson, P. G., \& Sincich T. (1998). Statistics for business and economics ( $7^{\text {th }}$ ed.). Upper Saddle River, NJ: Prentice Hall.

Meek, G., Taylor, H., Dunning, K., \& Klafehn, K. (1987). Business statistics. Boston, MA: Allyn \& Bacon.

Meek G. E \& Turner, S. J. (1983) Statistical analysis for business decisions. Boston, MA: Houghton Mifflin.

Mendenhall, W. \& Beaver, R. J. (1992). A course in business statistics ( $^{\text {rd }}$ ed.). Boston, MA: PWS-Kent.

Neter, J., Kutner, M., Nachtsheim, C., \& Wasserman, W. (2005). Applied linear statistical models ( $5^{\text {th }}$ ed.). Boston, MA: McGraw-Hill.

Neter, J., Wasserman, W., \& Whitmore, G. A. (1993). Applied statistics (4 $^{\text {th }}$ ed.). Boston, MA: Allyn and Bacon. 


\section{CEYHUN O. OZGUR}

Newbold, P. (1991). Statistics for business and economics ( $3^{\text {rd }}$ ed.). Englewood Cliffs, NJ: Prentice Hall.

Pelosi, M., \& Sandifer, T. (2002). Doing statistics for business with Excel: Data, inference, and decision making ( $2^{\text {nd }}$ ed.). New York, NY: John Wiley and Sons, Inc.

Ramsey, P. H. (1990). 'One-and-a-half-tailed' tests of significance. Psychological Reports, 66(2), 653-654. doi:10.2466/pr0.1990.66.2.653

Scheffé, H. (1959). The analysis of variance. New York, NY: J. Wiley \& Sons.

Siegel, A. F. (1997). Practical business statistics (4 ${ }^{\text {th }}$ ed). Chicago, IL: Irwin.

Sincich, T. (1996). Business statistics by example ( $5^{\text {th }}$ ed.). Upper Saddle River, NJ: Prentice Hall.

Taguchi, G. (1986). Introduction to quality engineering. White Plains, NY:

Kraus International Publications.

Watson, C., Billingsley, P., Croft, D. J., \& Huntsberger, D. (1993). Statistics for management and economics ( $5^{\text {th }} \mathrm{ed}$.). Boston, MA: Allyn and Bacon.

Weiers, R. M. (2002). Introduction to business statistics $\left(4^{\text {th }} \mathrm{ed}\right.$.). New York, NY: Duxbury. 